\title{
Pengaruh Model Pembelajaran Kooperatif Tipe Teams Games Tournament terhadap Kemampuan Berfikir Tingkat Tinggi Siswa
}

(Kuasi Eksperimen Di SMAN 1 Cililin Kabupaten Bandung Barat- Provinsi Jawa Barat pada kompetensi dasar perdagangan internasional di kelas XI IPS)

\section{Dewi Setianingsih ${ }^{1 *}$, Tjutju Yuniarsih ${ }^{2}$, dan Rozmitha Dewi Yuniarti Rozali $^{3}$ \\ ${ }^{1,2,3}$ Program Pendidikan Ekonomi, Sekolah Pasca Sarjana UPI \\ ${ }^{*}$ E-mail: dewi.setianingsih16@student.upi.edu}

\begin{abstract}
Abstrak: Penelitian ini bertujuan untuk mengetahui pengaruh model pembelajaran kooperatif tipe Teams Games Tournament (TGT) terhadap kemampuan berfikir tingkat tinggi (HOTS) siswa pada kompetensi dasar perdagangan internasional. Penelitian ini menggunakan metode deskriptif kuantitatif dengan bentuk penelitian kuasi eksperimen. Subyek penelitiannya adalah siswa kelas XI IPS SMA Negeri 1 Cililin tahun pelajaran 2017/2018. Instrumen pengumpulan data menggunakan tes. Berdasarkan hasil analisis diperoleh nilai signifikasi model sebesar 0,009 dengan nilai p-value sig lebih kecil dari 0,05, yang berarti bahwa terdapat pengaruh model pembelajaran kooperatif tipe TGT disertai media ular tangga terhadap kemampuan berfikir tingkat tinggi (HOTS), dengan nilai N Gain sebesar 0,35194.
\end{abstract}

Kata Kunci: Teams Games Tournament, kemampuan berfikir tingkat tinggi, media ular tangga.

UTILITY: Jurnal IImiah Pendidikan dan Ekonomi

Website : http://journal.stkipnurulhuda.ac.id/index.php/utility

Permalink: https://journal.stkipnurulhuda.ac.id/index.php/utility/article/view/313

How to cite (APA): Setianingsih, D. (2018). Pengaruh Model Pembelajaran Kooperatif Tipe Teams Games Tournament terhadap Kemampuan Berfikir Tingkat Tinggi Siswa. UTILITY: Jurnal IImiah Pendidikan Dan Ekonomi, 2(2), 72-84

This is an open access article distributed under the terms of the Creative Commons Attribution 4.0 International License, which permits unrestricted use, distribution, and reproduction in any medium, provided the original work is properly cited.

\section{PENDAHULUAN}

Arah pendidikan saat ini tidak hanya pada hasil belajar secara umum saja, tetapi harus memikirkan kepada pengembangan kemampuan berfikir tingkat tinggi yang disebut dengan istilah HOTS (high Order Thinking Skill). Selama beberapa dekade mengembangkan dan meningkatkan HOT, siswa 
merupakan sasaran pendidikan yang utama (Fisher, 2006; Marzano, 2009; Yen \& Halili, 2015). Komitmen terhadap HOT ini relevan dengan pertumbuhan ekonomi global, pengembangan teknologi informasi dan komunikasi (TIK), ekonomi berbasis pengetahuan dan dunia yang serba cepat (Yen \& Halili, 2015). Kenyataannya, HOT adalah keterampilan yang sangat dibutuhkan setiap individu dalam lingkungan pendidikan (Yen \& Halili, 2015). Fisher (2006) percaya bahwa pengembangan HOT pada siswa sangat cocok untuk menanamkan pembelajaran seumur hidup bagi mereka. Dengan kata lain, dibutuhkan siswa yang terus belajar dalam menghadapi tuntutan dunia nyata (Vijayaratnam, 2012 dalam Yen \& Halili, 2015)

Tantangan global berupa perkembangan ilmu pengetahuan dan teknologi yang sangat pesat pada abad ke 21 ini memerlukan sumberdaya manusia yang berkualitas tinggi dan memiliki modal intelektual berupa keterampilan berpikir, sikap ilmiah dan keterampilan bekerjasama. Terkait dengan hal ini, maka guru harus menyadari bahwa siswa tidak hanya membutuhkan pengetahuan berupa fakta dan konsep-konsep saja tetapi lebih penting lagi siswa perlu dibekali dengan keterampilan berpikir.

Kemampuan berfikir tingkat tinggi (HOT) merupakan kemampuan di atas tingkat pemahaman yang meliputi kegiatan aplikasi, analisis, sintesis dan evaluasi dalam memproses informasi (Zohar, 1999 dalam jurnal Yen \& Halili, 2015). Hal ini sesuai dengan anggapan bahwa HOT mencakup setiap kemampuan berpikir yang membutuhkan lebih dari sekadar mengingat atau penghafalan informasi (Ivie, 1998; Underbakke, Borg \& Peterson, 1993) dalam jurnal (Yen \& Halili, 2015). Tujuan peningkatan kemampuan berpikir tingkat tinggi pada siswa adalah untuk mengembangkan keterampilan siswa dalam mendiagnosis, memberi umpan balik tentang tingkat pemikiran, dan mendorong cara berpikir yang lebih baik (Abosalem, 2016)

Kategori pemikiran tingkat tinggi telah diadaptasi dari tes PISA Sains OECD (Fensham \& Bellocchia, 2013). Sejalan dengan hal tersebut, fakta di lapangan menunjukan bahwa mutu pendidikan di Indonesia sangatlah memprihatinkan. Berdasarkan tes Programme for International Student Assesment (PISA) yang diadakan oleh OECD ( Organisation for Economic Co-operation and Development) yang merupakan studi internasional tentang prestasi membaca, matematika dan ilmu pengetahuan alam siswa sekolah berusia 15 tahun, dari 76 negara yang ikut berpartisipasi dalam tes PISA tahun 
2015 Indonesia menduduki posisi 69 (OECD, 2014). Posisi Indonesia menempati posisi 10 terbawah. Rendahnya prestasi siswa tersebut harus dijadikan motivasi agar para pendidik terus berbenah supaya kualitas pendidikan Indonesia dapat meningkat. Berdasarkan Trends in International Mathematics and Science Study (TIMSS), siswa Indonesia hanya mampu berada di rangking ke-37 dari 44 negara berkembang dengan kemampuan ilmu pengetahuan yang baik (Gonzales et al., 2004).

SMAN 1 Cililin sudah menggunakan kurikulum 2013, mata pelajaran ekonomi terbagi kedalam tiga kelompok materi, materi ekonomi mikro dipelajari di kelas X, materi ekonomi makro dipelajari di kelas XI, sedangkan di kelas XII siswa mempelajari materi akuntansi. Berdasarkan hasil wawancara dengan pihak sekolah, Nilai UN ekonomi SMAN 1 Cililin belum masuk ke dalam kategori baik, selama 5 tahun hanya masuk klasifikasi cukup (C) bahkan D pada tahun 2014 dan 2017. Nilai rata-rata selama 6 tahun terakhir belum mampu mencapai nilai di atas 60, tentu saja fenomena di atas perlu menjadi perhatian semua pihak.

Rendahnya nilai Ujian nasional di SMAN 1 Cililin bisa disebabkan oleh terbatasnya kemampuan siswa dalam menganalisis dan memecahkan masalah. Hal tersebut dapat dilihat dari distribusi siswa yang mampu mengerjakan soal ujian pada tingkat kemampuan analisis, evaluasi dan mencipta $(\mathrm{C} 4, \mathrm{C} 5, \mathrm{C6})$ pada taksonomi Bloom. Berikut data distribusi nilai siswa kelas XI IPS dalam penilaian harian materi kebijakan ekonomi, soal terdiri dari 6 soal yang termasuk kategori high order thinking (HOT). 
Pengaruh Model Pembelajaran Kooperatif Tipe Teams Games Tournament terhadap Kemampuan Berfikir Tingkat Tinggi Siswa

Tabel 1. Distribusi Hasil Penilaian Harian Semester Genap pada Materi Kebijakan Ekonomi tahun 2018 kelas XI IPS

\begin{tabular}{|c|c|c|c|c|c|c|}
\hline \multirow{2}{*}{$\begin{array}{c}\text { Rentang } \\
\text { nilai }\end{array}$} & \multicolumn{2}{|c|}{ XI IPS 1} & \multicolumn{2}{|c|}{ XI IPS 2} & \multicolumn{2}{|c|}{ XI IPS 3} \\
\hline & jumlah & $\%$ & jumlah & $\%$ & jumlah & $\%$ \\
\hline $91-100$ & - & & & & - & \\
\hline $81-90$ & - & & - & & - & \\
\hline $71-80$ & - & & - & & - & \\
\hline $61-70$ & - & & - & & - & \\
\hline $51-60$ & - & & - & & - & \\
\hline $41-50$ & 2 & 5,3 & 1 & 2,6 & 1 & 2,9 \\
\hline $31-40$ & 3 & 7,9 & 7 & 18,4 & 4 & 11,4 \\
\hline $21-30$ & 13 & 34,2 & 9 & 23,7 & 18 & 51,4 \\
\hline $11-20$ & 19 & 50,0 & 18 & 47,4 & 9 & 25,7 \\
\hline $0-10$ & 1 & 2,6 & 3 & 7,9 & 3 & 8,6 \\
\hline TOTAL & 38 & 100,0 & 38 & 100,0 & 35 & 100,0 \\
\hline
\end{tabular}

Dari tabel 1 terlihat bahwa dari 3 kelas XI IPS, tidak ada peserta didik yang mencapai ketuntasan minimal (KKM) sebesar 67, peserta didik hanya mampu mencapai nilai 41 - 50 dengan prosentase yang sangat kecil. Prosentase terbesar kemampuan anak menjawab soal pada rentang nilai 11 20 di kelas XI IPS 1 dan XI IPS 2, rentang nilai 21 - 30 di kelas XI IPS 3.

Untuk mengatasi masalah rendahnya hasil belajar siswa, pendekatan yang digunakan adalah teori kontruktivisme yang dikemukakan Vygosky. Adanya interaksi antar kelompok siswa, dapat menghasilkan pembelajaran dan outcome yang lebih baik. Vygotsky berpendapat bahwa anak-anak mengembangkan konsep-konsep lebih sistematis, logis, dan rasional sebagai akibat dari interaksi dengan seorang penolong yang ahli. Perkembangan kognitif seseorang selain ditentukan oleh individu sendiri secara aktif, juga oleh lingkungan sosial yang aktif pula. Kontruktivisme menekankan bahwa pembelajaran kooperatif dapat memudahkan peserta didik terlibat dalam proses pembelajaran dalam restrukturisasi kognitif materi baru (Lee \& $\mathrm{Ng}$, 1998; Vygotsky, 1978)

Hasil penelitian Johnson dan rekan menunjukkan bahwa pembelajaran kooperatif dapat meningkatkan prestasi dan produktivitas yang lebih tinggi (yaitu dorongan untuk belajar) dari kompetisi antarpribadi atau bekerja individual, dan konsisten di semua mata pelajaran (Seni bahasa, membaca, matematika, IPA, IPS, psikologi, pendidikan jasmani), untuk semua kelompok umur (dasar, menengah, perguruan tinggi, dewasa) (Gillies \& Ashman, 2003) 
Salah satu tipe model pembelajaran kooperatif adalah tipe Teams Games Tournament (TGT). Penerapan model pembelajaran kooperatif tipe TGT dapat meningkatkan motivasi, keaktifan dan hasil belajar siswa (David L. DeVries, Edwards, \& Wells, 1974; Devries, 2015; Dewi, Mulyani, \& Mulyani, 2016; Edwards, Keith J.; DeVvies, 1974; Fajri, Martini, \& C.S, 2012; Slavin, 1985; Susilowati, 2016; Wahyu Nur Musyafa, 2015). Dalam proses belajar mengajar dengan tipe TGT ini diharapakan terdapat kompetisi antar kelompok, siswa dapat saling berinteraksi sosial, bekerja sama dan termotivasi untuk menjadi kelompok terbaik (Dewi et al., 2016; M. van Wyk, 2011).

\section{METODE}

Penelitian ini dilakukan di SMA Negeri 1 Cililin Bandung Barat pada kelas XI semester 2 tahun pelajaran 2017/2018. Penelitian ini menggunakan metode kuasi eksperimen. Teknik pengambilan data dilakukan dengan tes untuk mengukur kemampuan berfikir tingkat tinggi. Instrumen tes kemampuan berfikir tingkat tinggi diuji oleh pakar untuk menilai kelayakan soal tes. Instrumen tes berbentuk uraian sebanyak 6 soal. Tes dilakukan sebanyak 2 kali, di awal pembelajaran dilakukan pretest dengan memberikan seluruh soal, sedangkan posttes dilakukan sebanyak 3 kali setelah setiap siklus selesai dilaksanakan. Soal posttest disesuaikan dengan materi pelajaran. Hipotesis penelitian ini adalah: terdapat pengaruh model pembelajaran kooperatif tipe Team-Games-Tournament (TGT) terhadap kemampuan berfikir tingkat tinggi (HOTS) siswa

Untuk menganalisis data, peneliti menggunakan perhitungan inferensial dengan bantuan program SPSS 24 dan untuk menghitung seberapa besar pengaruh model pembelajaran kooperatif tipe TGT terhadap kemampuan berfikir tingkat tinggi dilihat dari nilai Normalisasi Gain. Tinggi rendahnya gain yang dinormalisasi (N-gain) dapat diklasifikasikan sebagai berikut: (1) jika $\mathrm{g} \geq 0,7$, maka $\mathrm{N}$-gain yang dihasilkan termasuk kategori tinggi; (2) jika $0,7>\mathrm{g} \geq 0,3$, maka $\mathrm{N}$-gain yang dihasilkan termasuk kategori sedang, dan (3) jika $\mathrm{g}<0,3$ maka $\mathrm{N}$-gain yang dihasilkan termasuk kategori rendah. $\mathrm{N}-$ Gain dapat dihitung dengan rumus $n$ gain $=\frac{s_{\text {post }}-S_{\text {pre }}}{\text { smaks }- \text { s pre }}$ 


\section{HASIL DAN PEMBAHASAN}

\section{Hasil}

Data kemampuan berpikir tingkat tinggi yang dideskripsikan dalam penelitian ini adalah skor rata-rata posttes yang diperoleh subjek penelitian dari tes kemampuan berfikir tingkat tinggi terkait kompetensi dasar perdagangan internasional. Pengujian statitistik dilakukan terhadap hasil pretest dan posttest kelas eksperimen (TGT) yang terdiri dari 41 siswa. Berdasarkan statistik deskriptif diperoleh hasil sebagai berikut:

Tabel 2. Deskriptif Statistik Kemampuan Berfikir Tingkat Tinggi Kelas Eksperimen (TGT)

\begin{tabular}{lrrrrr}
\hline \multicolumn{7}{c}{ Descriptive Statistics } \\
\hline Pretest & \multicolumn{1}{c}{ Minimum } & Maximum & Mean & Std. Deviation \\
post_HOTS & 41 & 0 & 30 & 7,83 & 6,511 \\
Valid N (listwise) & 41 & 15 & 80 & 40,27 & 17,226 \\
\hline
\end{tabular}

Dari tabel 1.2 tersebut terlihat bahwa rata - rata (mean) kemampuan berfikir tingkat tinggi sebelum treatment (prestest) pada kelas eksperimen (TGT) sebesar 7,83, sedangkan setelah treatment (posttest) memperoleh nilai rata - rata kemampuan berfikir tingkat tinggi sebesar 40,27, dapat dilihat bahwa nilai rata - rata kemampuan berfikir tingkat tinggi siswa mengalami peningkatan. Pada pretest nilai terendah yang diperoleh siswa adalah sebesar 0, ada siswa yang sama sekali tidak bisa menjawab soal yang diberikan dan skor tertinggi sebesar 30, sedangkan untuk skor terendah pada posttest sebesar 15 dan tertinggi sebesar 80 dari skor maksimum 100

Pengukuran terhadap efektivitas penggunaan metode TGT yang disertai media ular tangga dapat dilihat pada nilai rata - rata gain yang ternormalisasi dari skor pretest dan postest kemampuan berfikir tingkat tinggi siswa. Hasil prestes, postest dan nilai gain kemampuan berfikir tingkat tinggi pada kompetensi dasar perdagangan internasional di kelas eksperimen dapat dilihat pada tabel 1.3 tentang peningkatan kemampuan berfikir tingkat tinggi. 
Dewi Setianingsih' TjutjuYuniarsih, dan Rozmitha Dewi Yuniarti Rozali

Tabel 3. Peningkatan Kemampuan Berfikir Tingkat Tinggi pada Kelas Eksperimen

\begin{tabular}{ccccc}
\hline & Rata -rata & & & \\
Data & Skor & Peningkatan & N Gain & Kriteria N Gain \\
\hline Pretest & 7,83 & 32,44 & 0,35194 & Sedang \\
Posttest & 40,27 & & & \\
\hline
\end{tabular}

Berdasarkan tabel 1.3 terlihat bahwa rata - rata peningkatan kemampuan berfikir tingkat tinggi siswa pada mata pelajaran ekonomi di kelas eksperimen (XI IPS 2) yang mendapat treatment metode TGT disertai media pembelajaran ular tangga berada pada kategori sedang dengan nilai normalisasi gain sebesar 0,35194 .

Sebelum melakukan uji hipotesis, peneliti melakukan uji prasyarat penelitian berupa uji normalitas dan homogenitas. Hasil uji normalitas pada hasil posttes kemampuan berfikir tingkat tinggi pada kelas eksperimen dapat dilihat pada tabel 1.4.

Tabel 4. Hasil Uji Normalitas dan Homogenitas Kemampuan Berfikir Tingkat Tinggi

\begin{tabular}{|c|c|c|c|c|c|c|c|}
\hline \multicolumn{4}{|c|}{ Tests of Normality } & \multicolumn{4}{|c|}{ Homogenitas } \\
\hline \multirow[t]{2}{*}{ Metode } & \multicolumn{3}{|c|}{ Kolmogorov-Smirnov ${ }^{a}$} & \multicolumn{4}{|c|}{ Levene's Test of Equality of Error Variances ${ }^{a}$} \\
\hline & Statistic & $D f$ & Sig. & $F$ & $d f 1$ & $d f 2$ & Sig. \\
\hline$\overline{T G T}$ &, 123 & 41 &, 118 & 437 & 3 & 75 & ,821 \\
\hline
\end{tabular}

Dari tabel 1.4 terlihat bahwa hasil uji normalitas kemampuan berfikir tingkat tinggi siswa pada KD perdagangan internasional mata pelajaran ekonomi pada kelas eksperimen yang diberikan perlakuan model pembelajaran kooperatif tipe TGT menunjukkan nila sig $0,118>\alpha(0,05)$ yang berarti data berdistribusi normal. Dan hasil uji homogenitas diperoleh nilai signifikansi levene's di atas 0,05 yakni 0, 821 maka berdasarkan kriteria uji dapat disimpulkan bahwa tes kemampuan berfikir tingkat tinggi kedua kelas berasal dari populasi yang mempunyai varians yang sama.

Jadi data tes kemampuan berfikir tingkat tinggi pada kelas eksperimen termasuk ke dalam kategori normal dan homogen, oleh itu maka uji statistik dapat dilanjutkan kepada uji hipotesis dengan menggunakan uji analysis of variance (ANOVA). 
Pengaruh Model Pembelajaran Kooperatif Tipe Teams Games Tournament terhadap Kemampuan Berfikir Tingkat Tinggi Siswa

Tabel 5. Hasil Uji ANOVA Pengaruh Model Pembelajaran Kooperatif Tipe TGT terhadap Kemampuan Berfikir Tingkat Tinggi

Tests of Between-Subjects Effects

Dependent Variable: HOTS

\begin{tabular}{llllllll}
\hline \multicolumn{1}{c}{ Source } & \multicolumn{2}{c}{ Type III Sum of } & \multicolumn{2}{c}{ Mean } & & \multicolumn{2}{c}{ Partial Eta } \\
Squares & Df & Square & $F$ & Sig. & Squared \\
\hline Corrected Model & $6973,850^{a}$ & 5 & 1394,770 & 8,426 &, 000 &, 360 \\
Intercept & 79631,465 & 1 & 79631,465 & 481,063 &, 000 &, 865 \\
Model & 1178,494 & 1 & 1178,494 & 7,119 &, 009 &, 087 \\
\hline
\end{tabular}

a. R Squared $=, 360$ (Adjusted R Squared $=, 317$ )

Dari tabel 1.5 dapat dilihat bahwa signifikansi model adalah 0,009, jika dibandingkan dengan kriteria pengujian tingkat siginifikansinya $<0,05$ maka terdapat pengaruh model pembelajaran kooperatif terhadap kemampuan berfikir tingkat tinggi (HOTS) siswa ( $\eta$ square $=0,087 ; \mathrm{F}=7,119 ; \mathrm{p}=0,009$ $<0,05)$.

\section{Pembahasan}

Dalam penelitian ini variabel yang diteliti adalah Model pembelajaran kooperatif tipe TGT (X) yang disertai media pembelajaran ular tangga. Sebelum dilaksanakan pembelajaran dan sesudah pembelajaran dilakukan pretest dan posttest.

Berdasarkan hasil pengujian statistik diperoleh hasil yang menunjukkan bahwa nilai signifikansi model adalah 0,009. Nilai sig ini lebih kecil dari 0,05 sehingga dapat disimpulkan bahwa terdapat pengaruh model pembelajaran kooperatif terhadap kemampuan berfikir tingkat tinggi (HOTS) siswa.

Hasil penelitian ini sejalan dengan penelitian Eggen dan Kauchak (1996) dalam jurnal (Sumampouw, 2011) menyatakan bahwa berpikir tingkat tinggi termasuk berpikir kreatif dan berpikir kritis. Kemampuan berpikir tingkat tinggi dapat diberdayakan dengan memberdayakan keterampilan metakognitif. Keterampilan metakognitif terkait strategi maupun pelatihan metakognitif dan dapat dikembangkan melalui pembelajaran kooperatif (Green, Mc Donald, O’Donnell, Dansereau, 1994 dalam Sumampouw, 2011)

Dickie (2006) dan Berry (2008) dalam jurnal (M. M. Van Wyk, 2011) yang meyatakan bahwa TGT efektif dalam meningkatkan prestasi siswa dalam belajar. Menurut Adam dan Hamm (1990) dalam jurnal (M. M. Van Wyk, 2011) "Kolaborasi antara teman sebaya membantu anak-anak yang sangat muda untuk belajar bagaimana mempertimbangkan berbagai sudut 
pandang. Dan ketika anak-anak pada tingkat perkembangan yang berbeda bekerja sama untuk mengeksplorasi perbedaan pendapat, mereka semua meningkatkan kemampuan berpikir mereka".

Micheal M. van Wyk dalam jurnalnya yang berjudul The Effects of Teams-Games-Tournaments on Achievement, Retention, and Attitudes of Economics Education Students, menyatakan bahwa TGT mempunyai pengaruh yang signifikan terhadap hasil belajar, sikap dan kemampuan retensi siswa dalam mata pelajaran ekonomi (M. M. Van Wyk, 2011).

Model pembelajaran kooperatif tipe TGT disertai media permainan ular tangga dapat meningkatkan kemampuan berfikir tingkat tinggi karena pada saat pembelajaran berlangsung siswa melakukan diskusi untuk mengidentifikasi masalah, menganalisis, dan memecahkan masalah yang diberikan oleh guru serta menerapkan konsep materi pada permasalahan yang baru. Dilanjutkan dengan presentasi atas hasil diskusi menyebabkan siswa termotivasi untuk memahami semua konsep yang diberikan. Tahapan selanjutnya adalah permainan atau kuis yang diberikan oleh guru berupa soalsoal isian singkat. Perolehan nilai individu akan diakumulasi menjadi nilai kelompok Tahapan TGT berikutnya adalah turnamen berupa permainan ular tangga. Setiap kelompok mengutus anggotanya ke tiap papan permainan untuk menyelesaikan soal-soal yang ada di papan permainan, sama halnya dengan kuis, nilai setiap anggota akan diakumulasi menjadi nilai kelompok. Kegiatan kuis dan turnamen akan menyebabkan siswa termotivasi untuk belajar dan siswa yang mempunyai kemampuan lebih tinggi akan lebih termotivasi untuk membimbing anggota kelompoknya agar bisa menjadi kelompok terbaik, karena hal tersebut dapat tercapai jika siswa dalam kelompoknya saling bantu untuk memahami konsep dan materi. Hal ini senada dengan yang dikemukakan oleh (Nachiappan \& Rahman, 2014) bahwa permainan ular tangga dapat meningkatkan perkembangan kognitif siswa yang mengalami kesulitan belajar. Permainan ular tangga mampu membangun minat siswa untuk belajar. Selain itu, bermain ular tangga juga dapat meningkatkan keterampilan sosial di antara para siswa. Mereka dapat berinteraksi lebih baik dengan orang lain dan mereka dapat mengikuti permainan dan menyelesaikan permainan dengan sukses (Nachiappan \& Rahman, 2014).Tahapan terakhir adanya penghargaan yang diberikan oleh guru untuk kelompok terbaik. 
Pembelajaran yang seperti itu akan mengembangkan potensi siswa dalam menganalisis alternatif solusi permasalahan hingga pengambilan keputusan pemecahan masalah serta mengembangkan sikap kerjasama dan gotong royong yang akan menjadi bekal dalam menghadapi permasalahan permasalahan di dunia nyata. Dalam pendekatan pembelajaran yang berpusat pada siswa, pengetahuan akan dibangun oleh siswa sendiri dengan mengeksplorasi beberapa situasi dan masalah dunia nyata Dengan demikian, guru diharapkan dapat membuat dan memunculkan masalah (materi pembelajaran) yang sangat dekat dengan kehidupan sehari-hari siswa. Ini akan mendukung dan mendorong siswa untuk lebih terlibat dalam proses belajar mengajar, baik secara individu maupun kelompok, terutama dalam mengamati, menyelidiki, dan menarik kesimpulan menarik dari data yang diberikan, atau membuat hipotesis. Dalam kondisi seperti itu, kreativitas, keterampilan, dan kemampuan siswa diberdayakan dan dikembangkan dengan baik. Pemahaman konsep yang dipahami akan lebih berarti (Saragih \& Napitupulu, 2015).

\section{KESIMPULAN}

Model pembelajaran kooperatif tipe TGT teruji berpengaruh secara signifikan terhadap kemampuan berfikir tingkat tinggi (HOTS) siswa. Efektivitas penggunaan model pembelajaran tipe TGT yang disertai media ular tangga dapat dilihat dari nilai $\mathrm{N}$ Gain sebesar 0,35194, yang berarti sebesar 35,19\% kemampuan berfikir tingkat tinggi dipengaruhi oleh model pembelajaran kooperatif tipe TGT pada kompetensi dasar perdagangan internasional di SMAN 1 Cililin.

\section{UCAPAN TERIMAKASIH}

Terimakasih kepada semua pihak yang telah mendukung sehingga penelitian ini dapat selesai, terutama pada keluarga kecil ku, para dosen Pendidikan Ekonomi SPS UPI atas ilmu dan bimbingannya, guru-guru di SMAN 1 Cililin yang telah memberikan dukungan dan motivasi kepada peneliti. 


\section{REFERENSI}

Abosalem, Y. (2016). Assessment Techniques and Students' Higher-Order Thinking Skills, 4(1), 1-11. https://doi.org/10.11648/j.ijsedu.20160401.11

David L. DeVries, Edwards, K. J., \& Wells, E. H. (1974). Teams-GamesTournament in the Social Studies Classroom: Effects on Academic Achievement, Student Attitudes, Cognitive Beliefs, and Classroom Climate, 55.

Devries, D. L. (2015). Teams-Games-Tournament A Gaming Technique That Fosters Learning, 7(1), 21-33.

Dewi, A. K., Mulyani, S., \& Mulyani, B. (2016). Penerapan Model Pembelajaran Teams Games Tournaments (TGT) Disertai Video Compact Disk (VCD) dan Teka Teki Silang (TTS) untuk Meningkatkan Minat dan Hasil Brlajar Kimia pada Materi Konsep Materi dan Perubahannya Kelas X SMK Muhammadiyah 2 Sragen. Jurnal Pendidikan Kimia (JPK), 5 No 3(3), 87-91.

Edwards, Keith J.; DeVvies, D. L. (1974). The Effects of Teams- Games Tournament and Two InstructionLl Variations on Classroom Process, Student Attitudes, and Student Achievement.

Fajri, L., Martini, K., \& C.S, A. N. (2012). Upaya peningkatan proses dan hasil belajar kimia materi koloid melalui pembelajaran kooperatif tipe TGT (Teams Games Tournament) dilengkapi dengan teka-teki. Jurnal Pendidikan Kimia (JPK), 1(1), 89-96.

Fensham, P. J., \& Bellocchia, A. (2013). Higher Order Thinking in Chemistry Curriculum and its Assessment Author: Thinking Skills and Creativity. https://doi.org/10.1016/j.tsc.2013.06.003

Fisher, R. (2006). Thinking Skills to Thinking Schools: Ways to Develop Children $\hat{a} €^{\mathrm{TM}} \mathrm{s}$ Thinking and Learning Thinking Skills to Thinking Schools: Ways to Develop Children â $€^{\mathrm{TM}} \mathrm{s}$ Thinking and Learning, (October 2014), 37-41. https://doi.org/10.1080/0300443991530104

Gillies, R. M., \& Ashman, A. F. (2003). Co-operative learning: the social and intellectual outcomes of learning in groups. https://doi.org/10.4324/9780203465264

Gonzales, P., Guzmán, J. C., Partelow, L., Pahlke, E., Jocelyn, L., Kastberg, D., \& Williams, T. (2004). Highlights From the Trends in International 
Mathematics and Science Study (TIMSS) 2003. Online.

Humphreys, B., Johnson, R. T., \& Johnson, D. W. (1982). Effects Of Cooperative , Competitive , And Individualistic Learning On Students , Achievement In Science Class, 19(5), 351-356.

Marzano, R. J. (2009). How classroom teachers approach the teaching of thinking, (January 2015), 37-41. https://doi.org/10.1080/00405849309543591

Nachiappan, A. S., \& Rahman, N. A. (2014). Snake and Ladder Games in Cognition Development on Students. Journal of Advanced Research in Social and Behavioural Sciences ISSN (Online): 2462-1951| Vol. 3, No. 2. Pages 152-161, 2016, 3(2), 217-229.

OECD. (2014). PISA 2012 Results in Focus. Programme for International Student Assessment, 1-44. https://doi.org/10.1787/9789264208070-en

Saragih, S., \& Napitupulu, E. (2015). Developing Student-Centered Learning Model to Improve High Order Mathematical Thinking Ability, 8(6), 104112. https://doi.org/10.5539/ies.v8n6p104

Slavin, R. E. (1985). learning to cooperate cooperating to learn.

Slavin, R. E. (2006). Research on Cooperative Learning: an international perspective, (June 2013), 37-41.

Sumampouw, H. M. (2011). Keterampilan Metakognitif dan Berpikir Tingkat Tinggi dalam Pembelajaran Genetika ( Artikulasi Konsep dan Verifikasi Empiris ), (1986), 23-39.

Susilowati, D. (2016). Studi Komparasi Hasil Belajar Akuntansi Dengan Penerapan Metode Pembelajaran Teams Games Tournament (Tgt) Dengan Metode Ceramah Bervariasi Pada Kompetensi Dasar Jurnal Khusus Siswa Kelas Xii Ips Sma Muhammadiyah 01 Pati. Economic Education Analysis Journal, 5(1), 346-362.

van Wyk, M. (2011). The Effects of Teams-Games-Tournaments on Achievement, Retention, and Attitudes of Economics Education Students. Journal Social Science, 26(3), 183-193.

Wahyu Nur Musyafa, R. D. D. (2015). Pengaruh Model Pembelajaran Kooperatif Teams Games Tournament (TGT) Terhadap Prestasi Belajar Mata Pelajaran Teknik Pegelasan. E-Jurnal Pendidikan Teknik Mesin, 3(Model Pembelajaran), 371-378.

Wyk, M. M. Van. (2011). The Effects of Teams-Games-Tournaments on 
Dewi Setianingsih' TjutjuYuniarsih, dan Rozmitha Dewi Yuniarti Rozali

Achievement, Retention, and Attitudes of Economics Education Students, 26(3), 183-193.

Yen, T. S., \& Halili, S. H. (2015). Effective Teaching Of Higher-Order Thinking (HOT), 3(2), 41-47. 